\title{
Extending Metal-to-Polyoxometalate Charge Transfer Lifetimes: The Effect of Heterometal Location
}

\author{
Elliot N. Glass, ${ }^{[a]}$ John Fielden, ${ }^{[a, c, d]}$ Alexey L. Kaledin, ${ }^{[b]}$ Djamaladdin G. Musaev, $*[b]$ \\ Tianquan Lian*[a] and Craig L. Hill*[a]
}

[a] Mr E. N. Glass, Dr. J. Fielden, Prof. Dr. T. Lian, Prof. Dr. C. L. Hill

Department of Chemistry

Emory University

1515 Dickey Drive, Atlanta, GA 30322 (USA)

Fax: (+1) 404-727-6076

E-mail: chill@emory.edu

[b] Dr. A. L. Kaledin, Dir. Dr. D. G. Musaev

Cherry L. Emerson Center for Scientific Computation

Emory University

1515 Dickey Drive, Atlanta, GA 30322 (USA)

[c] Dr. J. Fielden

WestCHEM, School of Chemistry

University of Glasgow

University Avenue, Glasgow G12 8QQ (UK)

[d] Dr. J. Fielden (current affiliation)

School of Chemistry

University of East Anglia

Norwich, NR4 7TJ (UK)

\begin{abstract}
In an effort to develop robust molecular sensitizers for solar fuel production, we examine the electronic structure and photodynamics of transition-metal-substituted polyoxometalates (POMs), a novel class of compound in this context. Experimental and computational techniques including femtosecond (fs) transient absorption spectroscopy have been used to study the cobalt-containing Keggin POMs, $\left[\mathrm{Co}^{\mathrm{II}} \mathrm{W}_{12} \mathrm{O}_{40}\right]^{6-}(\mathbf{1 a}),\left[\mathrm{Co}^{\mathrm{III}} \mathrm{W}_{12} \mathrm{O}_{40}\right]^{5-}(\mathbf{2 a}),\left[\mathrm{SiCo}^{\mathrm{II}}\left(\mathrm{H}_{2} \mathrm{O}\right) \mathrm{W}_{11} \mathrm{O}_{39}\right]^{6-}(\mathbf{3 a})$, and $\left[\mathrm{SiCo}^{\mathrm{III}}\left(\mathrm{H}_{2} \mathrm{O}\right) \mathrm{W}_{11} \mathrm{O}_{39}\right]^{5-} \mathbf{( 4 a )}$, finding the longest lived charge transfer excited state so far observed in a POM and elucidating the electronic structures and excited state dynamics of these compounds at an unprecedented level. All species exhibit a biexponential decay in which early dynamic processes with time constants in the fs domain yield longer lived excited states which decay with time constants in the ps to ns domain. The initially formed states of 1a and $\mathbf{3 a}$ are considered to result from metal-topolyoxometalate charge transfer (MPCT) from $\mathrm{Co}^{\mathrm{II}}$ to $\mathrm{W}$, while the longer-lived excited state of $\mathbf{1 a}$ is tentatively assigned to a localized intermediate MPCT state. The excited state formed by the tetrahedral cobalt(II) centered heteropolyanion (1a) is far longer-lived ( $\tau=420 \mathrm{ps}$ in $\mathrm{H}_{2} \mathrm{O} ; \tau=1700 \mathrm{ps}$ in $\mathrm{MeCN}$ ) than that of 3a $\left(\tau=1.3 \mathrm{ps}\right.$ ), where the single $\mathrm{Co}^{\mathrm{II}}$ atom is located in a pseudo-octahedral addendum site. Short-lived states are observed for the two $\mathrm{Co}^{\mathrm{III}}$ containing heteropolyanions $\mathbf{2 a}(\tau=4.4 \mathrm{ps})$ and $4 \mathbf{a}(\tau=6.3 \mathrm{ps})$ and assigned solely to $\mathrm{O} \rightarrow \mathrm{Co}^{\mathrm{III}}$ charge transfer. The dramatically extended lifetime for $\mathbf{1 a} v s \mathbf{3 a}$ is ascribed to a structural change permitted by the coordinatively flexible central site, weak orbital overlap of the central Co with the polytungstate framework, and putative transient valence trapping of the excited electron on a single $\mathrm{W}$ atom, a phenomenon not noted previously in POMs.
\end{abstract}

\section{Introduction}

Chromophores based on oxo-bridged heterobimetallic groups (M-O-M'; $\mathrm{M}=\mathrm{Zr}^{\mathrm{IV}}, \mathrm{Ti}^{\mathrm{IV}} ; \mathrm{M}^{\prime}=\mathrm{Cu}^{\mathrm{I}}, \mathrm{Ce}^{\mathrm{III}}, \mathrm{Sn}^{\mathrm{II}}$ ) supported on mesoporous substrates have recently shown themselves to be promising alternatives to metal oxide semiconductors, and organic/metallo-organic chromophores in photocatalytic solar fuel production. ${ }^{[1]}$ In these materials, visible absorption results from photoinduced formation of long lived metal-to-metal charge transfer (MMCT) excited states that can be coupled with multi-electron transfer catalysts. Thus, such MMCT chromophores have the potential to side-step the problems of oxidative degradation of metallo-organic materials such as $\left[\mathrm{Ru}(\mathrm{bpy})_{3}\right]^{2+},{ }^{[2]}$ and the challenge of engineering metal oxides with the appropriate combination of band gap, electron/hole diffusion length, recombination rate and conduction band edge potential. ${ }^{[3]}$ Even so, surface-supported species are more difficult to characterize, optimize and interface with catalysts than molecular chromophores. 
Inspired by these heterobimetallic MMCT assemblies, we recently embarked upon the study of transition metal substituted polyoxometalates (POMs) as molecular inorganic MMCT (or MPCT, metal-to-polyoxometalate charge transfer) chromophores. POMs have not yet been systematically explored as tunable electron-accepting chromophores, ${ }^{[4]}$ but are excellent candidates because of their stability (oxidative and thermal) and ability to accommodate multiple heterometals. We found that $\mathrm{Re}^{\mathrm{I}}$ carbonyls supported by lacunary Wells-Dawson anions and Krebs dimers show extended visible absorption due to Re $\mathrm{e}^{\mathrm{I}}$-to-POM charge transfer, but the excited state lifetimes of these species $(<2 \mathrm{ps})$ are too short to be attractive for application in solar devices. ${ }^{[5]}$ Here, we study the electronic structure and excited state dynamics of a representative family of transition-metal-substituted POMs, the cobalt-containing Keggin derivatives: $\left[\mathrm{Co}^{\mathrm{II}} \mathrm{W}_{12} \mathrm{O}_{40}\right]^{6-}(\mathbf{1 a}), \quad\left[\mathrm{Co}^{\mathrm{III}} \mathrm{W}_{12} \mathrm{O}_{40}\right]^{5-} \quad(\mathbf{2 a}), \quad\left[\mathrm{SiCo}^{\mathrm{II}}\left(\mathrm{H}_{2} \mathrm{O}\right) \mathrm{W}_{11} \mathrm{O}_{39}\right]^{6-} \quad(\mathbf{3 a})$ and $\left[\mathrm{SiCo}^{\mathrm{III}}\left(\mathrm{H}_{2} \mathrm{O}\right) \mathrm{W}_{11} \mathrm{O}_{39}\right]^{5-}(\mathbf{4 a}) .^{[6]}$ This systematic approach facilitates the in-depth elucidation of POM excited state properties as a function of the coordination site and oxidation state of the transition-metal electron donor. The dramatically longer lived $(\tau=420$ ps in $\mathrm{H}_{2} \mathrm{O} ; \tau=1700$ ps in $\mathrm{MeCN}$ ) excited state of $\mathbf{1 a}$ is consistent with the ability of the central Co site to undergo structural distortions, poorer orbital overlap between this site and the reduced tungstate framework, and a possible valence-trapped intermediate.

\section{Results and Discussion}

Calculated Ground State Geometries and Electronic Structures: Our study comprises four cobalt-containing POMs - the cobalt-centered Keggin anions $\left[\mathrm{Co}^{\mathrm{II}} \mathrm{W}_{12} \mathrm{O}_{40}\right]^{6-}(\mathbf{1 a})$ and $\left[\mathrm{SiCo}^{\mathrm{II}}\left(\mathrm{H}_{2} \mathrm{O}\right) \mathrm{W}_{11} \mathrm{O}_{39}\right]^{6-}(\mathbf{2 a})$, and the cobalt substituted counterparts, $\left[\mathrm{SiCo}^{\mathrm{II}}\left(\mathrm{H}_{2} \mathrm{O}\right) \mathrm{W}_{11} \mathrm{O}_{39}\right]^{6-}(\mathbf{3 a})$ and $\left[\mathrm{SiCo}^{\mathrm{III}}\left(\mathrm{H}_{2} \mathrm{O}\right) \mathrm{W}_{11} \mathrm{O}_{39}\right]^{5-}(\mathbf{4 a})$, in which a $\mathrm{Co}$ atom replaces one of the W addendum atoms. This allows study of the effects of transition metal location and oxidation state on the nature and lifetime of the MPCT excited state. Compounds 1a and 2a have been well-studied since they were first synthesized by Baker and McCutcheon in 1956 - however investigations of the photodynamics of simple transition-metal containing POMs are entirely lacking.

As Keggin anions, all four clusters have super-tetrahedral structures, with a tetrahedral heteroatom (Co or $\mathrm{Si})$ at the center (Figure 1). Their experimentally determined and calculated metal-oxygen bond lengths are summarized in Table 1, and full calculated geometries are provided in the SI (Table S1). Crystallographic information is only included for anions 1a and 2a, because positional disorder prevents extraction of meaningful information on the Co atoms of $\mathbf{3 a}$ and $\mathbf{4 a}$. Note that while several previous studies have addressed the crystal structures of $\mathbf{1 a}$ and $\left.\mathbf{2 a}{ }^{[6,}{ }^{[6, g}, 7\right]$ the pentapotassium salt of $\mathbf{1 a}$ used in this study, $\mathrm{K}_{5} \mathrm{H}\left[\mathrm{Co}^{\mathrm{II}} \mathrm{W}_{12} \mathrm{O}_{40}\right] \cdot 15 \mathrm{H}_{2} \mathrm{O}(\mathbf{1})$, is crystallographically characterized for the first time.

Our crystal structures of cobalt-centered 1a and $\mathbf{2 a}$ are consistent with the literature, in showing Co-O bond lengths that are indicative of the Co oxidation state. ${ }^{32,33,48}$ Thus $\mathrm{Co}^{\mathrm{II}}-\mathrm{O}^{1}$ in $\mathbf{1 a}$ is significantly longer than $\mathrm{Co}^{\mathrm{III}}-\mathrm{O}^{1}$ in $\mathbf{2 a}(1.900(12)$ vs. 1.805(5) $\AA$ ), an observation well reproduced by our computed geometries for their $\mathrm{S}=3 / 2$ (1a) and $\mathrm{S}=2$ (2a) ground electronic states. Other computed and crystallographically determined bond distances for $\mathbf{1 a}$ and $\mathbf{2 a}$ are also in good agreement, the small differences being within expectations for crystallographic and gas phase calculated structures. The calculated ground state spins are also consistent both with previous studies, ${ }^{[6 \mathrm{c}, 6 \mathrm{~h}, \mathrm{i}]}$ and with expectations for tetrahedral $\mathrm{d}^{7}$ and $\mathrm{d}^{6}$ ions based on crystal field theory. Thus, the electronic configuration of the ground state of $\mathbf{3 a}$ is $\left\{\ldots[17 \mathrm{e}(\mathrm{O})]^{4}[18 \mathrm{e}(\mathrm{Co})]^{4}\left[33 \mathrm{t}_{2}(\mathrm{Co})\right]^{3}[19 \mathrm{e}(\mathrm{W})]^{0} \ldots\right\}$, where $17 \mathrm{e}(\mathrm{O})$ are doubly occupied orbitals of the $\mathrm{W}-\mathrm{O}-\mathrm{W}$ bridging O-center, $18 \mathrm{e}$ are doubly occupied d-orbitals of the Co-center, $33 \mathrm{t}_{2}$ the singly occupied d-orbitals of Co-center, and 19e is an unoccupied orbital of the $\mathrm{W}$-centers. Oxidation of 1a to 2a results in removal of one electron from the doubly occupied $18 \mathrm{e}$ orbital of the Co-center, and a small Jahn-Teller distortion that reduces the total symmetry of the anion from $\mathrm{T}_{\mathrm{d}}$ (for $\mathbf{1 a}$ ) to $\mathrm{D}_{2 \mathrm{~d}}$ (for $\mathbf{2 a}$ ). The resulting ground electron configuration for $\mathbf{2 a}$ is $\left\{\ldots\left[\mathrm{a}_{1}(\mathrm{Co})\right]^{2}\left[\mathrm{~b}_{1}(\mathrm{Co})\right]^{1}\left[\mathrm{~b}_{2}(\mathrm{Co})\right]^{1}[\mathrm{e}(\mathrm{Co})]^{2}\left[\mathrm{a}_{1}(\mathrm{~W})\right]^{0}\left[\mathrm{~b}_{1}(\mathrm{~W})\right]^{0} \ldots\right\}$. It is worth noting that the 1e-reduction of $2 \mathbf{a}$ yields $1 \mathbf{a}$, but not a heteropoly blue species, which is also consistent with previous findings. $\left.{ }^{[6]}\right]$

The calculated structures of $\mathbf{3 a}$ and $\mathbf{4 a}$, with addendum Co sites, also show shortening of the Co-O bonds upon oxidation $\left(\mathrm{Co}-\mathrm{O}^{2}\right.$ to $\left.\mathrm{Co}-\mathrm{O}^{5}\right)$, with the exception of the bond to the internal oxygen $\mathrm{O}^{1}$ of the $\mathrm{SiO}_{4}$ unit. The calculated ground spin state of $3 \mathbf{a}$ is a quartet, $\mathrm{S}=3 / 2$, as would be expected for a high spin, octahedral $\mathrm{d}^{7}$ ion, and calculations find that the Cocenter has almost 2.75 unpaired electrons. The doubly occupied MOs of 3a are Co-O bonding orbitals, and the singly occupied MOs are Co-d orbitals. In this case, frontier orbital analysis indicates that oxidation of $\mathbf{3 a}$ to $\mathbf{4 a}$ results in loss of one electron from the doubly occupied $(\mathrm{CoO})$ orbital. As a result, the $\mathrm{Co}^{\mathrm{III}}$ center in $4 \mathbf{a}$ bears 1.75 unpaired electrons, essentially giving a triplet $(S=1)$ ground state. However, it should be noted that the calculated energetic separation between this triplet state, and the expected diamagnetic $(\mathrm{S}=0)$ state is very close $(\mathrm{ca} .0 .6 \mathrm{kcal} / \mathrm{mol})$. As the triplet wavefunction is cleaner and more accurate than the open-shell singlet wavefunction, computationally the UV-visible spectra are assigned starting from the triplet state.

UV-visible Spectroscopic and Electrochemical Studies: Comparison of the UV-visible absorption spectra of $\mathbf{1}$ to $\mathbf{4}$, in combination with the results of our calculations and electrochemical experiments, allows a comprehensive assignment of the electronic transitions of these compounds. This includes the MPCT transitions excited in the transient experiments.

The UV-visible absorption spectra of compounds 1 to $4(350$ to $750 \mathrm{~nm})$ are displayed in Figure 2. At shorter wavelengths $(<300 \mathrm{~nm})$, all four compounds show strong UV absorptions arising from the $\mathrm{O}_{2 \mathrm{p}} \rightarrow \mathrm{W}_{5 \mathrm{~d}}$ charge transfer (CT) transitions common 
to all polyoxotungstates. However, compared to transition metal-free POMs such as $\left[\mathrm{SiW}_{12} \mathrm{O}_{40}\right]^{4-}$ and $\left[\mathrm{PW}_{12} \mathrm{O}_{40}\right]^{3-}$, the absorption spectra of $\mathbf{1}$ to $\mathbf{4}$ tail more significantly into the visible and show additional features arising from the cobalt d-orbitals. For cobaltcentered anions 1a and 2a, the main observations are a broad transition at $625 \mathrm{~nm}$ in $\mathbf{1}$ that is absent in $\mathbf{2}$, and a strong peak at 389

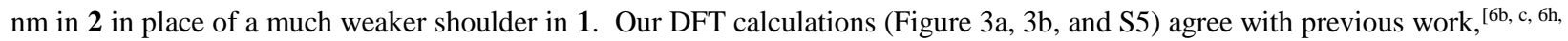
${ }^{6 \mathrm{k}]}$ indicating that the feature at $625 \mathrm{~nm}$ (calculated $\sim 650 \mathrm{~nm}$ ) is associated with the ${ }^{4} \mathrm{~A}_{2} \rightarrow{ }^{4} \mathrm{~T}_{1} \mathrm{~d}-\mathrm{d}$ transition of the tetrahedral Co ${ }^{\mathrm{II}}$ ion in 1a while the peak at $389 \mathrm{~nm}$ (calculated range $\sim 375-450 \mathrm{~nm}$ for 2a) arises from the $\mathrm{O} \rightarrow \mathrm{Co}$ CT transitions which are present in $\mathrm{Co}^{\mathrm{III}}$-based 2a because the Co $e$ orbital is partially occupied. The spectra of anions $\mathbf{3 a}$ and $\mathbf{4 a}$, with a pseudo-octahedral addendum Co site, are significantly different. Compound 3 shows a d-d transition centered at $546 \mathrm{~nm}$ that resembles that of $\left[\mathrm{Co}^{\mathrm{II}}\left(\mathrm{H}_{2} \mathrm{O}\right)_{6}\right]^{2+}$, although the broken octahedral symmetry causes the extinction coefficient to be substantially higher. The broad ${ }^{1} \mathrm{~A}_{1} \rightarrow{ }^{1} \mathrm{~T}_{1} \mathrm{~d}$-d transition for 4 is centered at $692 \mathrm{~nm}$, while the peak at $453 \mathrm{~nm}$ is ascribed to a ${ }^{1} \mathrm{~A}_{1} \rightarrow{ }^{1} \mathrm{~T}_{2} \mathrm{~d}-\mathrm{d}$ transition. ${ }^{[8]}$ Calculated absorption spectra for anions $\mathbf{3 a}$ and $4 \mathbf{a}$ (Figure $3 \mathrm{c}$ and $3 \mathrm{~d}$ ) reproduce the dipole allowed Co d-d transitions seen at longer wavelengths in both spectra. Calculations for $4 \mathbf{a}$ also indicate that the transition at $\sim 450 \mathrm{~nm}$ has Co d-d character along with a strong $\mathrm{O} \rightarrow \mathrm{W}$ signature. The short wavelength regimes of both anions are dominated by $\mu_{2}-\mathrm{O} \rightarrow \mathrm{W}$ and $\mu_{2}-\mathrm{O} \rightarrow \mathrm{CoO}$ transitions, with the majority being non-charge-transfer in nature.

In anions containing $\mathrm{Co}^{\mathrm{II}}$, it is expected that $\mathrm{Co} \rightarrow \mathrm{W} \mathrm{CT}$ transitions should be observed. For 1a, electrochemically determined potentials for the $\mathrm{Co}^{2+/ 3+}$ couple and first polytungstate reduction (Figure S2) allow estimation of an energy difference of $1.29 \mathrm{eV}$ $(961 \mathrm{~nm})$ between the highest energy $\mathrm{Co}^{\mathrm{II}}$-based orbitals and the polytungstate LUMO ${ }^{[9]}$ Indeed, several overlapping absorption peaks are observed between 1000 and $1400 \mathrm{~nm}$ (Figure S4), which have been attributed to ligand-field and charge-transfer transitions. ${ }^{[6 \mathrm{~h}]}$ Detailed computational analysis of the lower-lying excited states of $\mathbf{1 a}$ also finds $\mathrm{e}(\mathrm{Co}) \rightarrow \mathrm{t}_{2}(\mathrm{~W}) \mathrm{CT}$ character in three dipole forbidden transitions at $\sim 1200 \mathrm{~nm}$, although this is dominated by $\mathrm{e}(\mathrm{Co}) \rightarrow \mathrm{t}_{2}(\mathrm{Co})$, i.e., non-CT Co d-d transitions (see Table S2). Combining the electrochemically estimated HOMO - LUMO gap with the $1.98 \mathrm{eV}$ (625 nm) $e$ to $t_{2} \mathrm{~d}$-orbital splitting allows prediction of higher energy $\mathrm{Co} \rightarrow \mathrm{W}$ transitions at $c a .3 .25 \mathrm{eV}(380 \mathrm{~nm})$, which have not been previously identified. ${ }^{[6 \mathrm{~h}, 6 \mathrm{k}]}$ This is supported by our calculations, which for 1a predict $\mathrm{e}(\mathrm{CoTd}) \rightarrow \mathrm{e}(\mathrm{W})$ and $\mathrm{t}_{2}(\mathrm{CoTd}) \rightarrow \mathrm{e}(\mathrm{W}) \mathrm{CT}$ transitions at $\sim 430 \mathrm{and} 510 \mathrm{~nm}$ respectively. These transitions are observed in the form of a gentle rise in absorption between 420 and $380 \mathrm{~nm}$, which may coincide with $\mathrm{O} \rightarrow$ Co transitions. In the case of pseudo-octahedral $\mathrm{Co}^{\mathrm{II}}$-based $\mathbf{3 a}$, examination of the excited state wavefunctions reveals a group of CT-like $\mathrm{Co} \rightarrow \mathrm{W}$ excitations in 3a near $320 \mathrm{~nm}$ which are obscured by $\mathrm{O} \rightarrow \mathrm{Co}$ and $\mathrm{O} \rightarrow \mathrm{W}$ processes. It therefore seems likely (and is experimentally demonstrated below) that excitation of either 1a or 3a at around $400 \mathrm{~nm}$ will cause transfer of an electron from Co to the polyoxotungstate framework, allowing study of the influence of the metal coordination site on excited state behavior.

Transient Absorption Spectra and Kinetics: Transient absorption spectra and kinetics of aqueous $\mathbf{1}$ at selected time delays after $400 \mathrm{~nm}$ excitation are shown in Figure 4a. Immediately following excitation, 1 produces broad, intense absorption features that rapidly decay within 5 ps. The initial excited state of 1 decays with a time constant of $\tau_{1}=730 \pm 40 \mathrm{fs}$, after which the overall shape of the difference spectrum does not change until full ground state recovery takes place. This second excited state species is much longer lived, with a transient spectrum showing a ground state bleach centered at $625 \mathrm{~nm}$ and absorption bands at $<500 \mathrm{~nm}$ and $>700 \mathrm{~nm}$. Clear isosbestic points are observed at $550 \mathrm{~nm}$ and $675 \mathrm{~nm}$, with single-exponential nonradiative decay dynamics, indicating decay of a single species to the ground state. The lifetime of this species, $\tau_{2}=420 \pm 30 \mathrm{ps}$, is far in excess of those measured for any transition-metal substituted polyoxometalate thus far. ${ }^{[5,10]}$

The excited state spectral features of $\mathbf{1}$ bear a strong resemblance to the inverted static ground state absorption spectra and $1 \mathrm{e}^{-}$-reduced forms of $\mathbf{1}$ (Figure 5). The initial short-lived species $\tau_{1}$ resembles a $1 \mathrm{e}^{-}$heteropoly blue, but with lower intensity than the simulated difference spectrum, ${ }^{[11]}$ presumably because the very short lifetime means that substantial decay has already occurred. Thus this strongly absorbing initial state is assigned as a metal-to-polyoxometalate CT (MPCT) excited state, which decays rapidly to a longer-lived intermediate state before ground state recovery. The long-lived excited state, $\tau_{2}$, exhibits a bleach at $625 \mathrm{~nm}$ that matches the ground state ${ }^{4} \mathrm{~A}_{2} \rightarrow{ }^{4} \mathrm{~T}_{1} \mathrm{~d}-\mathrm{d}$ transitions, and the broad absorption at $>700 \mathrm{~nm}$ resembles the heteropoly blue species formed by one-electron reduction of $\mathbf{1}^{[12]}$ The ground state bleach of the $\mathrm{Co}^{\mathrm{II}} \mathrm{d}-\mathrm{d}$ band reveals that an electron is photoexcited from the tetrahedral $\mathrm{Co}^{\mathrm{II}}$ center to the vacant tungstate $\mathrm{W}$ orbitals, and the intensity of this feature declines only very slightly between $\tau_{1}$ and $\tau_{2}$ However, the intensity of the heteropoly blue spectral features in $\tau_{2}$ are a fraction of those expected in a true $1 \mathrm{e}^{-}$ heteropoly blue, having features with extinction coefficients of only $\sim 100 \mathrm{~L} \mathrm{~mol}^{-1} \mathrm{~cm}^{-1}$. Regardless, placing an electron-rich metal at the center, rather than in the addendum of a POM anion appears to result in a dramatically extended (by two orders of magnitude) MPCT excited state lifetime. ${ }^{[5]}$

Both excited state spectra for $\mathbf{1}$ share similar features, though the ground state bleach is clearer for the longer lived process $\tau_{2}$. The spectra show unexpected absorptions $<500 \mathrm{~nm}$ which can be explained by red-shifting and intensification of the $\mathrm{O} \rightarrow \mathrm{Co}$ transition observed in $\mathbf{2}$, due to formation of a $\mathrm{Co}^{\mathrm{III}}$ center surrounded by a more strongly electron donating reduced tungstate framework. The transient spectrum for $\tau_{2}$ closely resembles a simulated difference spectrum in which a smaller contribution from the heteropoly blue is assumed. ${ }^{[13]}$ Reduced frameworks contain delocalized electrons which yield mixed valence heteropoly blues as the result of multiple tungsten atoms being structurally equivalent. The low intensity of the absorptions in $\tau_{2}$ may suggest that 
the electron is localized on one or a few of the tungstates instead of being delocalized across the entire framework. Consequently, this proposal implies that a transient structural change occurs that breaks the symmetry of the framework (vide infra).

The hypothesis that the weak heteropoly blue contribution to $\tau_{2}$ is the result of localized charge should be contrasted with the alternative of a low quantum yield process, whereby only $\sim 8 \%$ of the photoexcited electrons from $\tau_{1}$ would form $\tau_{2}$ and the remainder would collapse back to the ground state via internal conversion. If this were the case, however, one would expect to see a commensurate decrease in the contributions from $\mathrm{Co}^{\mathrm{III}}$ and the $\mathrm{Co}^{\mathrm{II}}$ ground state bleach. Instead, a simulated excited state spectrum very close to $\tau_{2}$ is produced by combining full contributions from spectra of 1 and 2 and $1 / 12^{\text {th }}$ that of a $1 \mathrm{e}^{-}$reduced heteropoly blue. This suggests that the heteropoly blue spectral signature observed in $\tau_{2}$ is weaker than expected because less of the tungsten framework is involved, not because electrons have returned to the Co atom.

Salt metathesis of $\mathbf{1}$ to $\mathbf{1 - T B A}$ was performed to measure the excited state lifetimes in an organic solvent. The electronic absorption spectrum of 1-TBA in MeCN (Figure S7) is nearly identical to that of $\mathbf{1}$ in water. The slight shift of the CoTd d-d band, with $\lambda_{\max }$ shifting to $628 \mathrm{~nm}$, is consistent with a central heteroatom that is largely isolated from the polytungstate framework and the solvent, showing minimal solvatochromism. ${ }^{[6 \mathrm{~b}, 7,14]}$ The excited state dynamics of 1-TBA show similar biphasic decay kinetics (Figure S8), with the initial excited state decaying with a time constant of $\tau_{1}=810 \pm 30 \mathrm{fs}$. Remarkably, the long-lived excited state component is extended by a factor of four, having a time constant of $\tau_{2}=1700 \pm 140 \mathrm{ps}$. This appreciable solvent dependence supports the notion of charge localization in the long-lived excited state. If the initial MPCT excited state is delocalized, a dipole moment does not exist in the molecule due to symmetry. As a result, the initial excited state shows minimal solvent dependence in going to a less polar solvent (730 fs in water vs. $810 \mathrm{fs}$ in $\mathrm{MeCN}$ ). On the other hand, the solvent dependence of $\tau_{2}$ suggests the presence of a charge transfer dipole moment, only possible if the electron residing on the polytungstate framework is localized to some degree. ${ }^{[15]}$ This is reminiscent of the charge localization that occurs in $\left[\mathrm{Ru}(\mathrm{bpy})_{3}\right]^{2+}$ on the ultrafast time scale. ${ }^{[16]}$ The nanosecond lifetime of $\tau_{2}$ in $\mathrm{MeCN}$ is consistent with the energy-gap law for nonradiative decay in intramolecular charge transfer excited states. Hydrogen bonding in water can also contribute to the shorter lifetime of $\tau_{2}$ in water, as protic media can contribute to nonradiative decay pathways due to favorable interaction with charge transfer states. ${ }^{[17]}$

To confirm that the location and oxidation state of cobalt are important to generation of the long-lived excited state, we studied the excited-state dynamics of 2 to 4 (Figure 4b-d). In 2 (oxidized analogue of 1), biphasic decay kinetics are also observed, but with complete decay to the ground state within around $20 \mathrm{ps}\left(\tau_{1}=220 \pm 50 \mathrm{fs} ; \tau_{2}=4.4 \pm 0.6 \mathrm{ps}\right)$. This provides further evidence that electron transfer from $\mathrm{Co}^{\text {II }}$ to the polytungstate ligand is responsible for the long-lived excited state in $\mathbf{1}$. Excitation of $\mathbf{2}$ at 400 $\mathrm{nm}$ should only involve the $\mathrm{O} \rightarrow$ Coe transition, as lowering of the CoTd Coe orbitals due to Jahn-Teller distortion ${ }^{[6 e, 6 \mathrm{~g}, 6 \mathrm{i}, \mathrm{j}]}$ increases the energy of the $\mathrm{Co} \rightarrow \mathrm{W}$ charge transfer transition, while lowering the energy of $\mathrm{O} \rightarrow \mathrm{Co}$ charge transfer. The resulting excited state consisting of a hole on an oxygen atom adjacent to a distorted $\mathrm{Co}^{\mathrm{II}}$ should recombine rapidly. Involvement of $\mathrm{Co} \rightarrow \mathrm{W}$ processes is unlikely as it would generate very high energy states containing $\mathrm{Co}^{\mathrm{IV}}$ and reduced tungstate. Electrochemical generation of $\left[\mathrm{Co}^{\mathrm{IV}} \mathrm{W}_{12} \mathrm{O}_{40}\right]^{4-}$ to provide a spectroscopic handle for $\mathrm{Co}^{\mathrm{IV}}$ in these systems has not been possible.

In anion 3a, the $\mathrm{Co}^{\mathrm{II}}$ is moved to a pseudo-octahedral addendum site, with a Si heteroatom. In this case, Cooh ${ }^{\mathrm{II}} \rightarrow \mathrm{W}$ charge transfer may occur. Transient spectral features (Figure 4c) suggest that it does, through formation of a bleach at $546 \mathrm{~nm}$ corresponding to the $\mathrm{CoOh}^{\mathrm{II}} \mathrm{d}-\mathrm{d}$ bands and a broad absorption at $>600 \mathrm{~nm}$ consistent with reduction of the polytungstate. An additional new absorption is seen at $440 \mathrm{~nm}$. Similar to 1a, the initially formed MPCT state rapidly decays $\left(\tau_{1}=570 \pm 40 \mathrm{fs}\right)$ to a less intense state featuring similar features bracketing the CoOh ${ }^{\text {II }} \mathrm{d}-\mathrm{d}$ bleach (Figure 6). ${ }^{[18]}$ However, the features of the second excited state decay much more quickly than in 1a (within $5 \mathrm{ps}$ ), although the weakness of the $546 \mathrm{~nm}$ feature has prevented accurate fitting and extraction of time constants for decay $\left(\tau_{2}=1.3 \pm 3.8 \mathrm{ps}\right.$ ). To complete the series, the ultrafast dynamics of 4 (oxidized analogue of 3, Figure 4d) exhibit a short-lived biphasic excited state $\left(\tau_{1}=400 \pm 150 \mathrm{fs} ; \tau_{2}=6.3 \pm 0.6\right.$ ps), where a single broad absorption at $470 \mathrm{~nm}$ rapidly decays to the baseline within $30 \mathrm{ps}$. In this case, the primary excited transition should be $\mathrm{O} \rightarrow \mathrm{Co} / \mathrm{W}$ mixed orbitals. Overall, these results strongly suggest that the long-lived excited state in $\mathbf{1}$ is linked to location of a $\mathrm{Co}^{\mathrm{II}}$ heterometal in the central, tetrahedral site of the anion 1a.

Briefly, we also note here that early time data ( 0.3 to $5 \mathrm{ps}$ ) for all four anions indicates broad, intense absorptions peaking between 400 and $500 \mathrm{~nm}$. Interpretation of these data is difficult due to the combination of dynamic processes associated with the initial excited state and the temporal resolution of the instrument $(\sim 150 \mathrm{fs})$, but their observation in all four anions suggests they are related to concurrent internal conversion and vibrational relaxation within the polytungstate framework (Table 2). For $\mathbf{1}$ and $\mathbf{3}$, these processes complete within 5 ps to yield secondary excited states. Different transitions are involved in $\mathbf{2}$ and $\mathbf{4}$, and the second excited state lifetime is likely the result of thermalization.

Origin of the long-lived excited state in anion 1a: Given the enormous difference in the excited state lifetimes of CoTd ${ }^{\text {II }}$-centered 1a and $\mathrm{Cooh}^{\mathrm{II}}$-substituted 3a, it appears that the coordination environment of Co must have an important influence on the nature of the excited state. In other words, a substantial barrier to ultrafast recombination must exist in 1a that does not exist in 3a.

Structural barriers to ground state recovery resulting from distorted excited state geometries are important in the photophysics of transition metal complexes. For example, substantial structural changes occurring on the ultrafast timescale have been reported for tetrahedral copper complexes, ${ }^{[19]}$ and structural distortions have been invoked as an explanation for the surprisingly long excited state lifetimes measured for silica supported MMCT heterodimers. ${ }^{[1 f]}$ Therefore, it is worth noting that 
the central heteroatom site of the $\left[\mathrm{X}^{\mathrm{n}+} \mathrm{W}_{12} \mathrm{O}_{40}\right]^{(8-\mathrm{n})-}$ Keggin anion shows considerable coordinative flexibility, with a brief survey of crystal structures indicating a range of central X-O distances from $c a .1 .53$ to $1.93 \AA .{ }^{[6 \mathrm{~g}]}$ This is because the preferences of the heteroatom $\mathrm{X}$ can be compensated by changes in the length of the relatively weak bond from $\mathrm{W}$ to the internal oxygen. ${ }^{[6 i]}$ In the case of $\left[\mathrm{Co}^{\mathrm{II}} \mathrm{W}_{12} \mathrm{O}_{40}\right]^{6-}(\mathbf{1 a})$ and $\left[\mathrm{Co}^{\mathrm{III}} \mathrm{W}_{12} \mathrm{O}_{40}\right]^{5-}(\mathbf{2 a})$ a shortening of Co-O bond lengths of approximately $0.1 \AA$ is observed upon moving from $\mathrm{Co}^{\mathrm{II}}$ to $\mathrm{Co}^{\mathrm{III}}$, accompanied by a small Jahn-Teller distortion and reduction in symmetry. The addendum coordination site is less flexible: the rather few positional disorder-free structures available for $\left[\mathrm{X}^{\mathrm{n}+} \mathrm{Z}^{\mathrm{m}+}(\mathrm{L}) \mathrm{W}_{11} \mathrm{O}_{39}\right]^{(12-\mathrm{n}-\mathrm{m})-}$ anions show relatively little variation in their average equatorial Z-O distances ( $c a .1 .94$ to $2.01 \AA$ ). ${ }^{[20]}$ Bond distances for Cooh ${ }^{\mathrm{II}}-\mathrm{O}$ (around $2.09 \AA$ in $\left.\left[\mathrm{Co}\left(\mathrm{H}_{2} \mathrm{O}\right)_{6}\right]^{2+}\right)^{[21]}$ are therefore likely to be compressed to around $2 \AA$ in $\mathbf{3 a}$, and may not contract much further upon transient oxidation to $\mathrm{Co}^{\mathrm{III}}\left(\left[\mathrm{Co}\left(\mathrm{H}_{2} \mathrm{O}\right)_{6}\right]^{3+}\right.$ has $\mathrm{Co}-\mathrm{O}$ distances of around $1.98 \AA$ ).$^{[22]}$ There is also less reorganization energy for Jahn-Teller distortion between octahedral $\mathrm{Co}^{\mathrm{II}}$ and $\mathrm{Co}^{\mathrm{III}}$ than for their tetrahedral $\mathrm{Co}^{\mathrm{II} / \mathrm{III}}$ counterparts. The shorter lifetime of the excited state of $\mathbf{3}$ could also be influenced by the presence of a labile aqua ligand, which may contribute additional vibrational relaxation pathways via hydrogen bonding and solute-solvent interactions. ${ }^{[23]}$

The degree of Jahn-Teller distortion during photo-excitation of $\mathbf{1}$ can be qualitatively evaluated by considering the reorganization energy, calculated by direct measurement of the self-exchange rates for the outer sphere electron transfer between 1a and 2a. ${ }^{[24]}$ A range of 23 to $85 \mathrm{kcal} \mathrm{mol}^{-1}(1.0$ to $3.7 \mathrm{eV})$ has been calculated for the total reorganization energy of the 1a/2a system. ${ }^{[14 \mathrm{~b}, 25]}$ The inner sphere reorganization energy, corresponding to the energy barrier for interconversion of the $\left[\mathrm{Co}^{\mathrm{II}} \mathrm{O}_{4}\right]^{6-}$ $/\left[\mathrm{Co}^{\mathrm{III}} \mathrm{O}_{4}\right]^{5-}$ tetrahedron, was measured as $11.05 \mathrm{kcal} \mathrm{mol}^{-1}(0.48 \mathrm{eV}) .{ }^{[24]}$ This large reorganization energy could easily account for the long excited-state lifetime of $\mathbf{1 a}$ by decreasing the rate of back-electron transfer between the polytungstate framework and Co ${ }^{\mathrm{III}}$. In the case of 3a, such a significant reorganization barrier is unlikely. Furthermore, the orbital overlap between the central $\mathrm{Co}^{\mathrm{II}}$ and the polytungstate framework is known to be poor, as multiple studies have established the electronic isolation of the central atom in 1a. ${ }^{[6 b, 7,14]}$ Consequently, the electronic coupling term will be lower for the tetrahedral central atom compared to that of the pseudo-octahedral addendum site. This will also contribute to a slower back-electron transfer rate, although it also lowers the oscillator strength of the initial transition (hence its weakness).

It is clear from the transient absorption data that the initially formed MPCT state of 1a rapidly decays to a second excited state with similar, though less intense, spectral features. The dynamic Jahn-Teller distortion in moving from $\mathrm{Co}^{\mathrm{II}}$ to $\mathrm{Co}^{\mathrm{III}}$ reduces the local symmetry of the tetrahedral $\left[\mathrm{Co}^{\mathrm{II}} \mathrm{O}_{4}\right]^{6-}$ heteroatom. Concurrently, the reduced polytungstate framework, normally composed of twelve structurally equivalent tungstates, is perturbed by the irregular $\left[\mathrm{Co}^{\mathrm{III}} \mathrm{O}_{4}\right]^{5-}$ tetrahedron. The heteropoly blue MPCT state subsequently collapses from a 12-fold delocalization to a 3-fold (delocalized across a single triad cap) or singlyreduced tungstate. Such a transient valence trap (illustrated in Scheme 1) would explain the spectral features of the long-lived excited state of 1a, with the long lifetime attributed to a localized electron impeded from returning to the ground state by a significant reorganization energy barrier. Valence trapping has been observed in other heteropoly blue complexes at low temperatures and in vanadium-substituted POMs, ${ }^{[26]}$ though this is the first time this has been proposed in the photophysical mechanism of a POM.

Intersystem crossing is a final factor that may contribute to the excited state lifetime of 1a. The initially formed FranckCondon state following excitation is ${ }^{4} \mathrm{MPCT}$, with four singly occupied Co orbitals, and is not energetically favorable. Intersystem crossing (ISC) should therefore occur to yield a ${ }^{6} \mathrm{MPCT}$ state. This most likely occurs within the same time scale as the dynamic Jahn-Teller distortion of the transient $\mathrm{Co}^{\mathrm{III}}$ e.g. within the $5 \mathrm{ps}$ it takes for the early dynamic process, $\tau_{1}$, to complete, suggesting an intersystem crossing rate constant in excess of $10^{12} \mathrm{~s}^{-1}$. Such fast rates for ISC have been previously demonstrated in $\left[\mathrm{Ru}(\mathrm{bpy})_{3}\right]^{2+},{ }^{[19 b]}$ a low-spin $\mathrm{Fe}^{\mathrm{II}}$ complex, ${ }^{[27]}$ and $\mathrm{Au}^{\mathrm{I}}$ naphthalene compounds, ${ }^{[28]}$ among others. However, it is important to note that ISC would also be expected to apply to MPCT excited states generated from octahedral $\mathrm{Co}^{\mathrm{II}}$, so this factor alone cannot account for the difference in excited state lifetimes.

In the context of molecular sensitizers for solar fuel production, 1a has the longest lived charge transfer excited state observed in a POM to date by more than two orders of magnitude. ${ }^{[5]}$ While still short compared to many organic and metal-organic photosensitizers, this extended lifetime is potentially chemically interceptable considering the femtosecond electron injection kinetics known for dye-sensitized metal oxides. ${ }^{[27,29]}$ Furthermore, 1a leverages the known thermal and oxidative stability of POMs by being exceptionally stable in solution and under irradiation. ${ }^{[30]}$ Further experiments to probe the photochemical reactivity and excited state properties of 1a are ongoing.

\section{Conclusion}

The polyoxometalate anions $\left[\mathrm{Co}^{\mathrm{II}} \mathrm{W}_{12} \mathrm{O}_{40}\right]^{6-}(\mathbf{1 a})$ and $\left[\mathrm{SiCo}^{\mathrm{II}}\left(\mathrm{H}_{2} \mathrm{O}\right) \mathrm{W}_{11} \mathrm{O}_{39}\right]^{6-}(\mathbf{3 a})$ both have MPCT excited states which are accessible with visible excitation. In the case of 1a, this state decays to a second excited state which is far longer-lived (at $420 \mathrm{ps}$ in $\mathrm{H}_{2} \mathrm{O}, 1700 \mathrm{ps}$ in $\mathrm{MeCN}$ ) than for any other polyoxometalate studied thus far. The lifetime of the MPCT excited state of 1a can be rationalized through geometric distortions - both shortening of Co-O bond distances and Jahn-Teller distortion - induced by the change in oxidation state at the Co center, and permitted by the more flexible central coordination site. This insight may help design new systems which combine the stronger visible extinction coefficients of our previous rhenium carbonyl systems, with 
longer lifetimes which might allow exploitation these chromophores in solar energy applications where their oxidative, photochemical and thermal stability is advantageous.

\section{Experimental Section}

General: All materials were purchased as ACS analytical or reagent grade and used as received, and syntheses were carried out in the ambient atmosphere. $\mathrm{K}_{5} \mathrm{H}\left[\mathrm{Co}^{\mathrm{II}} \mathrm{W}_{12} \mathrm{O}_{40}\right] \cdot 15 \mathrm{H}_{2} \mathrm{O}(\mathbf{1}),{ }^{[6 \mathrm{a}, \mathrm{b}, 6 \mathrm{~d}]} \mathrm{K}_{5}\left[\mathrm{Co}^{\mathrm{III}} \mathrm{W}_{12} \mathrm{O}_{40}\right] \cdot 20 \mathrm{H}_{2} \mathrm{O}(2),{ }^{[6 \mathrm{a}, \text { b, } 6 \mathrm{~d}]} \mathrm{K}_{6}\left[\mathrm{SiCo}^{\mathrm{II}}\left(\mathrm{H}_{2} \mathrm{O}\right) \mathrm{W}_{11} \mathrm{O}_{39}\right] \cdot 10 \mathrm{H}_{2} \mathrm{O}$ (3), ${ }^{[31]}$ and $\mathrm{Cs}_{5}\left[\mathrm{SiCo}^{\mathrm{III}}\left(\mathrm{H}_{2} \mathrm{O}\right) \mathrm{W}_{11} \mathrm{O}_{39}\right] \cdot 3 \mathrm{H}_{2} \mathrm{O}(\mathbf{4})^{[8]}$ were prepared based on published procedures (minor adaptations for $\mathbf{1}$ and 2 are detailed in the SI). Salt metathesis to prepare $\left(\mathrm{C}_{16} \mathrm{H}_{36} \mathrm{~N}\right)_{4} \mathrm{H}_{2}\left[\mathrm{Co}^{\mathrm{II}} \mathrm{W}_{12} \mathrm{O}_{40}\right](\mathbf{1}-\mathrm{TBA})$ was based on known procedures (detailed in the SI). ${ }^{[32]}$ The identities and purities of $\mathbf{1 - 4}$ were confirmed by infrared and UV-visible spectroscopy, thermogravimetric analysis, and X-ray diffraction. Infrared spectra ( $2 \%$ by weight in $\mathrm{KBr}$ ) were recorded on a Nicolet 6700 FT-IR spectrometer. Static electronic absorption spectra were acquired using an Agilent 8453 spectrophotometer equipped with a diode-array detector and Agilent 89090A cell temperature controller unit. Near infrared (NIR) spectra were acquired using a Shimadzu UV-3600 UV-VisNIR spectrophotometer. Thermogravimetric data were collected on ISI TGA 1000 and Perkin Elmer STA 6000 instruments. Xray diffraction data were acquired using a Bruker APEX II diffractometer with an Oxford Cryostream. Cyclic voltammograms were recorded on a BAS CV-50W electrochemical analyzer equipped with a glassy-carbon working electrode, a platinum wire auxiliary electrode and an $\mathrm{Ag} / \mathrm{AgCl}(3 \mathrm{M} \mathrm{NaCl}) \mathrm{BAS}$ reference electrode, using sodium sulfate $(0.250 \mathrm{M}$, $\mathrm{pH} 2)$ or lithium acetate $(0.250 \mathrm{M}, \mathrm{pH} 5)$ as buffer/electrolyte. All redox potentials are reported relative to this reference electrode $(\sim+202 \mathrm{mV}$ nominal difference between NHE and the BAS electrode). Two-electron reduced spectra of $\mathbf{1}$ and $\mathbf{3}$ were prepared by bulk electrolysis of $0.5 \mathrm{mM} 1$ and 3 in equivalent conditions to transient measurements, at $-0.49 \mathrm{~V}$ and $-1.0 \mathrm{~V} \mathrm{vs.} \mathrm{Ag} / \mathrm{AgCl}$, respectively. A glassy carbon mesh electrode was used as the working electrode. Static electronic absorption spectra were recorded of the reduced species immediately following electrolysis. The one-electron reduced spectra were approximated by scaling the two-electron reduced spectra by a one-half factor, consistent with the nature of heteropoly blue absorptions in Keggin POMs. ${ }^{[14 a]}$

Single Crystal X-ray Structural Determination: Compounds $\mathbf{1}$ and $\mathbf{2}$ were crystallized from water, compound $\mathbf{1}$ requiring almost complete evaporation of the solvent due to its high aqueous solubility. Suitable single crystals were selected under ambient conditions, mounted on a cryoloop using Paratone-N oil, and placed under the cryostream at $173 \mathrm{~K}$. Crystal evaluation and collection of X-ray diffraction intensity data were performed using a Bruker Apex II CCD diffractometer (Mo $\mathrm{K}_{\alpha}, \lambda=0.71073 \AA$ ) and data reduction was carried out using the Bruker APEXII program suite. ${ }^{[3]}$ Correction for incident and diffracted beam absorption effects were applied using numerical methods. ${ }^{[34]}$ Compound $\mathbf{1}$ crystallized in the space group $P 3_{2} 21$ and compound $\mathbf{2}$ in $P_{2} 22$ as determined by systematic absences in the intensity data, intensity statistics and the successful solution and refinement of the structure. Structure solution and refinement was carried out using the Bruker SHELXTL software package. ${ }^{[35]}$ The structures were solved by direct methods and refined against $F^{2}$ by the full matrix least-square technique. All non-H atoms were refined anisotropically, $\mathrm{H}$ atoms were not located or refined. Crystal data, data collection parameters and refinement statistics are summarized in Table 3. ORTEP representations of the cluster anions 1a and 2a are given in Figure S1.

Femtosecond Visible Transient Absorption Measurements: The femtosecond ( $0.1 \mathrm{ps}-1.2 \mathrm{~ns})$ transient absorption (TA) spectrometer used in this study was based on a regeneratively amplified Ti:sapphire laser system (Coherent Legend, $800 \mathrm{~nm}, 150$ fs, $3 \mathrm{~mJ} /$ pulse, $1 \mathrm{kHz}$ repetition rate) and the Helios spectrometer (Ultrafast Systems, LLC). The fundamental output from the regenerative amplifier was split in two with a $10 \%$ beam splitter, the majority being directed to generate the pump pulse and the reflected remainder used to generate the probe pulse. Pump pulses at $400 \mathrm{~nm}$ were generated by frequency-doubling of the fundamental pulse in a $\beta$-barium borate (BBO) crystal. The energy of the pump pulse was controlled by a variable neutral-density filter wheel. The pump pulse passed through a computer-controlled optical delay line and a chopper prior to passing through the sample. The visible probe was generated by attenuating and focusing $\sim 10 \mu \mathrm{J}$ of the $800 \mathrm{~nm}$ pulse into a 2 mm thick sapphire window to produce a white light continuum from $400 \mathrm{~nm}$ to $800 \mathrm{~nm}$. After collimation with an off-axis parabolic mirror, the white light was split into equal signal and reference beams. The reference beam was used to normalize the laser intensity fluctuation. The signal beam was collimated and focused on the sample coincident with the pump pulse beam using Al parabolic mirrors. The beam waists at the sample were 300 and $150 \mu \mathrm{m}$ for the pump and probe beam, respectively. Both the signal (after passing through the sample) and reference beams were focused into a CMOS array detector and detected at a frequency of $1 \mathrm{kHz}$, from which transient spectra and kinetics were recorded with Helios (Ultrafast Systems) software.

Samples were measured in a $1 \mathrm{~mm}$ path length quartz cuvette to minimize the transient solvent response. The solvent effect in neat buffered solvent was recorded immediately following each sample measurement. During the data collection the samples were constantly stirred by a magnetic stirrer to minimize localized thermal effects. No evidence of sample degradation was seen based on comparisons of electronic absorption spectra before and after TA experiments. All samples were filtered with a Whatman $0.2 \mu \mathrm{m}$ PES syringe filter prior to measurement. Detailed analysis of the transient spectra, temporal chirp correction, and quantitative kinetic analysis was performed using Ultrafast Systems Surface Xplorer Pro software. Global fit analysis via singular value decomposition was performed on all transient spectra. Both single wavelength kinetics and the principal kinetic components were fit to a multiexponential decay function convoluted with the Gaussian instrument response function (fwhm: $\sim 150$ 
fs).

Computational Studies: Geometries of the anions $\left[\mathrm{Co}^{\mathrm{II}} \mathrm{W}_{12} \mathrm{O}_{40}\right]^{6-}(\mathbf{1 a}),\left[\mathrm{Co}^{\mathrm{III}} \mathrm{W}_{12} \mathrm{O}_{40}\right]^{5-}(\mathbf{2 a}),\left[\mathrm{SiCo}^{\mathrm{II}}\left(\mathrm{H}_{2} \mathrm{O}\right) \mathrm{O}_{39} \mathrm{~W}_{11}\right]^{6-}(\mathbf{3 a})$ and $\left[\mathrm{SiCo}^{\mathrm{III}}\left(\mathrm{H}_{2} \mathrm{O}\right) \mathrm{O}_{39} \mathrm{~W}_{11}\right]^{5-}(\mathbf{4 a})$ were optimized at their several lower-lying electronic states, in the gas phase with no geometry constraints. Vibrational analyses were performed to ensure that all converged structures are true minima. In these calculations we used the spin-unrestricted DFT method (the hybrid M06L functional) ${ }^{[36]}$ in conjunction with the $\mathrm{D} 95 \mathrm{~V}^{[37]}$ basis sets for $\mathrm{O}$, and the lanl2dz basis with the associated Hay-Wadt ECPs ${ }^{[38]}$ for the W and Co atoms, which below will be referred to as "UM06L/lanl2dz". The basis set for $\mathrm{Si}$ was augmented by single polarization d-function $(\zeta=0.55)$. Electronic spectra and electric dipole transition moments for ground-to-excited state transitions were calculated at the optimized geometries of the ground states of the corresponding compounds using the time-dependent (TD) ${ }^{[39]}$ DFT, i.e. TD-UM06L/lanl2dz approach. Solvent effects were applied as single point calculations on top of the gas phase structures and approximated by the polarizable continuum model (PCM) ${ }^{[0]}$ employing the $\mathrm{UFF}^{[41]}$ radii for all atoms. All calculations were carried out with the Gaussian 09 software package. ${ }^{[42]}$

\section{Acknowledgements}

We thank William Rodríguez-Córdoba for assistance with the transient absorption spectrometer, Christopher James for early synthesis of 2, and Dr. Christopher C. Scarborough for use of his NIR spectrometer. J.F. is supported by a Marie Curie International Outgoing Fellowship within the $7^{\text {th }}$ European Union Framework Programme. This work was supported by the U. S. Department of Energy, Office of Basic Energy Sciences, Solar Photochemistry Program (DE-FG02-07ER15906) to C.L.H., T.L. and D.G.M. The authors gratefully acknowledge NSF MRI-R2 grant (CHE-0958205) and the use of the resources of the Cherry Emerson Center for Scientific Computation.

\section{References and Footnotes}

[1] a) W. Lin and H. Frei, J. Am. Chem. Soc. 2005, 127, 1610-1611; b) W. Lin and H. Frei, J. Phys. Chem. B 2005, 109, 4929-4935; c) H. Han and H. Frei, J. Phys. Chem. C 2008, 112, 16156-16159; d) H. Han and H. Frei, J. Phys. Chem. C 2008, 112, 8391-8399; e) X. Wu, W. W. Weare and H. Frei, Dalton Trans. 2009, 10114-10121; f) T. Cuk, W. W. Weare and H. Frei, J. Phys. Chem. C 2010, 114, 9167-9172; g) T. Takashima, A. Yamaguchi, K. Hashimoto and R. Nakamura, Chem. Commun. 2012, 48, 2964-2966; h) T. Takashima, R. Nakamura and K. Hashimoto, J. Phys. Chem. C 2009, 113, 17247-17253.

[2] P. K. Ghosh, B. S. Brunschwig, M. Chou, C. Creutz and N. Sutin, J. Am. Chem. Soc. 1984, 106, 4772-4783.

[3] a) B. Moshofsky and T. Mokari, Chem. Mater. 2012, 25, 1384-1391; b) L. F. Zhu, J. C. She, J. Y. Luo, S. Z. Deng, J. Chen and N. S. Xu, J. Phys. Chem. C 2010, 114, 15504-15509; c) G. K. Mor, H. E. Prakasam, O. K. Varghese, K. Shankar and C. A. Grimes, Nano Lett. 2007, 7, 2356-2364; d) B. M. Klahr, A. B. F. Martinson and T. W. Hamann, Langmuir 2010, 27, 461-468; e) S. Han, J. Li, X. Chen, Y. Huang, C. Liu, Y. Yang and W. Li, Int. J. Hydrogen Energy 2012, 37 , 16810-16816; f) W. J. Lee, P. S. Shinde, G. H. Go and E. Ramasamy, Int. J. Hydrogen Energy 2011, 36, 5262-5270.

[4] a) C. L. Hill, Chem. Rev. 1998, 98, 1-2; b) J. J. Borrás-Almenar, E. Coronado, A. Müller and M. T. Pope, Polyoxometalate Molecular Science. Proceedings of the NATO Advanced Study Institute, Tenerife, Spain from 25 August to 4 September 2001, Kluwer Academic Publishers, Dordrecht, 2003, p. 484.

[5] a) C. Zhao, Z. Huang, W. Rodríguez-Córdoba, C. S. Kambara, K. P. O’Halloran, K. I. Hardcastle, D. G. Musaev, T. Lian and C. L. Hill, J. Am. Chem. Soc. 2011, 133, 20134-20137; b) C. Zhao, C. S. Kambara, Y. Yang, A. L. Kaledin, D. G. Musaev, T. Lian and C. L. Hill, Inorg. Chem. 2013, 52, 671-678; c) C. Zhao, W. Rodríguez-Córdoba, A. L. Kaledin, Y. Yang, Y. V. Geletii, T. Lian, D. G. Musaev, C. L. Hill, Inorg. Chem. 2013, 52, 13490-13495.

[6] a) L. C. W. Baker and T. P. McCutcheon, J. Am. Chem. Soc. 1956, 78, 4503-4510; b) V. E. Simmons in Heteropoly Tungstocobaltoates and Tungstocobaltiates based on $\mathrm{CoO}_{4}$ Tetrahedra: Magnetic Properties, Spectra, Chemistry, and Structures, Vol. Boston University, Boston, 1953, p. 500; c) L. C. W. Baker, V. E. S. Baker, S. H. Wasfi, G. A. Candela and A. H. Kahn, J. Chem. Phys. 1972, 56, 4917-4923; d) A. L. Nolan, R. C. Burns and G. A. Lawrance, J. Chem. Soc., Dalton Trans. 1998, 3041-3047; e) R. Acerete, N. Casañ-Pastor, J. Bas-Serra and L. C. W. Baker, J. Am. Chem. Soc. 1989, 111, 6049-6056; f) G. Muncaster, G. Sankar, C. R. A. Catlow, J. M. Thomas, S. J. Coles and M. Hursthouse, Chem. Mater. 2000, 16-18; g) A. L. Nolan, C. C. Allen, R. C. Burns, D. C. Craig and G. A. Lawrance, Aust. J. Chem. 2000, 53, 59-66; h) J. M. Maestre, X. López, C. Bo, C. Daul and J.-M. Poblet, Inorg. Chem. 2002, 41, 1883-1888; i) J. M. Maestre, X. López, C. Bo, J.-M. Poblet and N. Casañ-Pastor, J. Am. Chem. Soc. 2001, 123, 3749-3758; j) F.-Q. Zhang, X.-M. Zhang, H.-S. Wu and H. Jiao, J. Phys. Chem. A 2007, 111, 159-166; k) K. Kojima and J. Matsuda, Bull. Chem. Soc. Jpn. 1985, 58, 821-825.

[7] N. Casan-Pastor, P. Gomez-Romero, G. B. Jameson and L. C. W. Baker, J. Am. Chem. Soc. 1991, 113, 5658-5663.

[8] T. J. R. Weakley and S. A. Malik, J. Inorg. Nucl. Chem. 1967, 29, 2935-2944.

[9] The same analysis cannot be performed on 3a (Figure S3), because the tungstate redox process cannot be cleanly observed at pH values in which the anion is stable. Based on the more oxidizing position of the $\mathrm{Co}^{2+/ 3+}$ couple in $\mathbf{3 a}$, it is expected that the same transition would occur at higher energy compared to 1a.

[10] Z. Huang in Charge Transfer Dynamics in Homogeneous and Heterogeneous Artificial Photosynthetic Systems. Ph.D. Dissertation, Emory University, Atlanta, GA, 2011, p. 221.

[11] The simulated excited state spectrum for $\mathbf{1}$ (Figure 5, blue line) was calculated by taking the 1e- reduced spectrum of $\mathbf{1}$, adding the spectrum for the oxidized species $\mathbf{2}$, and subtracting the ground state spectrum of $\mathbf{1}$ twice. The ground state spectrum of $\mathbf{1}$ was subtracted twice to remove the d-d band contribution from the $1 \mathrm{e}^{-}$reduced species as well as the ground state bleach, as expected in a simulated difference spectrum.

[12] M. T. Pope and G. M. Varga, Inorg. Chem. 1966, 5, 1249-1254.

[13] The second simulated excited state spectrum for $\mathbf{1}$ (Figure 5, red line) was calculated by subtracting the ground state spectrum of $\mathbf{1}$ from that of the oxidized species 2 , then adding a $1 / 12^{\text {th }}$ scaled spectrum of the $1 \mathrm{e}^{-}$reduced species from which $\mathbf{1}$ was previously subtracted. This assumes $100 \%$ formation of $\mathrm{Co}^{\mathrm{III}}$ from $\mathrm{Co}^{\mathrm{II}}$ during photoexcitation, scaled to a heteropoly blue contribution that closely resembles the observed transient measurement. 
[14] a) G. M. Varga, E. Papaconstantinou and M. T. Pope, Inorg. Chem. 1970, 9, 662-667; b) I. A. Weinstock, Chem. Rev. 1998, 98, $113-170$.

[15] a) J. V. Caspar and T. J. Meyer, J. Amer. Chem. Soc. 1983, 105, 5583-5590; b) E. M. Kober, B. P. Sullivan and T. J. Meyer, Inorg. Chem. 1984, 23 , $2098-2104$.

[16] a) S. Campagna, F. Puntoriero, F. Nastasi, G. Bergamini and V. Balzani in Photochemistry and Photophysics of Coordination Compounds: Ruthenium, Vol. 280 Eds.: V. Balzani and S. Campagna), Springer Berlin Heidelberg, 2007, pp. 117-214; b) A. T. Yeh, C. V. Shank and J. K. McCusker, Science 2000, 289, 935938.

[17] V. S. Pavlovich, ChemPhysChem 2012, 13, 4081-4093.

[18] The first simulated excited state spectrum for $\mathbf{3}$ was calculated the same way as performed for $\mathbf{1}$. The second excited state spectrum was most closely approximated by subtracting the ground state spectrum of $\mathbf{3}$ from that of the oxidized species $\mathbf{4}$, with no heteropoly blue contribution.

[19] a) M. Iwamura, S. Takeuchi and T. Tahara, J. Am. Chem. Soc. 2007, 129, 5248-5256; b) A. C. Bhasikuttan, M. Suzuki, S. Nakashima and T. Okada, J. Am. Chem. Soc. 2002, 124, 8398-8405.

[20] a) B. Li, S.-T. Zheng and G.-Y. Yang, Chin. J. Struct. Chem. 2009, 28, 531-536; b) D.-J. Li, S.-T. Zheng and G.-Y. Yang, Chin. J. Struct. Chem. 2009, 28, 655662; c) J.-W. Zhao, J. Zhang, S.-T. Zheng and G.-Y. Yang, Chin. J. Struct. Chem. 2008, 27, 933-942; d) M.-X. Li, K.-H. Wang and J.-Y. Niu, Chin. J. Struct. Chem. 2008, 27, 340-344; e) L. Lisnard, A. Dolbecq, P. Mialane, J. Marrot and F. Sécheresse, Inorg. Chim. Acta 2004, 357, 845-852; f) C. Pichon, A. Dolbecq, P. Mialane, J. Marrot, E. Rivière, M. Goral, M. Zynek, T. McCormac, S. A. Borshch, E. Zueva and F. Sécheresse, Chem. Eur. J. 2008, 14, 3189-3199; g) E. V. Radkov and R. H. Beer, Inorg. Chim. Acta 2000, 297, 191-198; h) M. Sadakane, D. Tsukuma, M. H. Dickman, B. Bassil, U. Kortz, M. Higashijima and W. Ueda, Dalton Trans. 2006, 0, 4271-4276; i) S. Reinoso, P. Vitoria, L. Lezama, A. Luque and J. M. Gutiérrez-Zorrilla, Inorg. Chem. 2003, 42, $3709-3711$.

[21] W. Zhang and Y.-T. Chen, Acta Crystallogr., Sect. E: Struct. Rep. Online 2009, 65, m1548.

[22] I. Stein and U. Ruschewitz, Z. Naturforsch., B: Chem. Sci. 2011, 66, 471-478.

[23] a) M. L. Bhaumik and L. J. Nugent, J. Chem. Phys. 1965, 43, 1680-1687; b) M. P. Hehlen, H. Riesen and H. U. Guedel, Inorg. Chem. 1991, 30, 2273-2277; c) H. Dong and R. A. Wheeler, Chem. Phys. Lett. 2005, 413, 176-181.

[24] P. G. Rasmussen and J. Brubaker, Carl H., Inorg. Chem. 1964, 3, 977-980.

[25] a) L. Eberson, J. Am. Chem. Soc. 1983, 105, 3192-3199; b) Z. Amjad, J.-C. Brodovitch and A. McAuley, Can. J. Chem. 1977, 55, 3581-3586; c) L. Eberson, New J. Chem. 1992, 16, 151-156; d) L. V. Kozhevnikov and O. A. Kholdeeva, Izv. Akad. Nauk SSSR, Ser. Khim. 1987, 528-533 (Eng. Transl.).

[26] a) J. Altenau, M. T. Pope, R. A. Prados and H. So, Inorg. Chem. 1975, 14, 417-421; b) R. A. Prados, P. T. Meiklejohn and M. T. Pope, J. Amer. Chem. Soc. 1974, 96, 1261-1263.

[27] J. E. Monat and J. K. McCusker, J. Am. Chem. Soc. 2000, 122, 4092-4097.

[28] R. A. Vogt, T. G. Gray and C. E. Crespo-Hernández, J. Am. Chem. Soc. 2012, 134, 14808-14817.

[29] a) H. N. Ghosh, J. B. Asbury and T. Lian, J. Phys. Chem. B 1998, 102, 6482-6486; b) H. N. Ghosh, J. B. Asbury, Y. Weng and T. Lian, J. Phys. Chem. B 1998, 102, 10208-10215; c) S. Ferrere and B. A. Gregg, J. Am. Chem. Soc. 1998, 120, 843-844; d) D. Kuciauskas, J. E. Monat, R. Villahermosa, H. B. Gray, N. S. Lewis and J. K. McCusker, J. Phys. Chem. B 2002, 106, 9347-9358.

[30] No evidence of decomposition is observed by electronic absorption spectroscopy after prolonged irradiation at $400 \mathrm{~nm}$. Solutions of $\mathbf{1}$ kept in aqueous buffer (pH 2-5), water, or MeCN for several months show no change in their absorption spectrum.

[31] A. Müller, L. Dloczik, E. Diemann and M. T. Pope, Inorg. Chim. Acta 1997, 257, 231-239.

[32] a) J. A. Mair, J. Chem. Soc. 1950, 1950, 2364-2372; b) D. K. Lyon, W. K. Miller, T. Novet, P. J. Domaille, E. Evitt, D. C. Johnson and R. G. Finke, J. Am. Chem. Soc. 1991, 113, 7209-7221.

[33] APEXII (Version 2.0-1), SAINT (Version 7.23A) and SADABS (Version 2004/1), Bruker AXS, Inc., Madison, WI, USA, 2005.

[34] P. Coppens, L. Leiserowitz and D. Rabinovich, Acta Crystallogr. 1965, 18, 1035-1038.

[35] SHELXTL (v 6.1), Bruker AXS, Inc., Madison, WI, USA, 2000.

[36] Y. Zhao and D. G. Truhlar, J. Chem. Phys. 2006, 125, 194101-194118.

[37] T. H. Dunning Jr. and P. J. Hay, Modern Theoretical Chemistry, Plenum, New York, 1976.

[38] P. J. Hay and W. R. Wadt, J. Chem. Phys. 1985, 82, 270-283.

[39] F. Furche and R. Ahlrichs, J. Chem. Phys. 2002, 117, 7433-7447.

[40] J. Tomasi, B. Mennucci and R. Cammi, Chem. Rev. 2005, 105, 2999-3094.

[41] A. K. Rappe, C. J. Casewit, K. S. Colwell, W. A. Goddard and W. M. Skiff, J. Am. Chem. Soc. 1992, 114, 10024-10035.

[42] Frisch, M. J., et al. Gaussian 09, Revision C.01; Wallingford CT, 2009. See SI for complete reference.

Figures and Schemes 

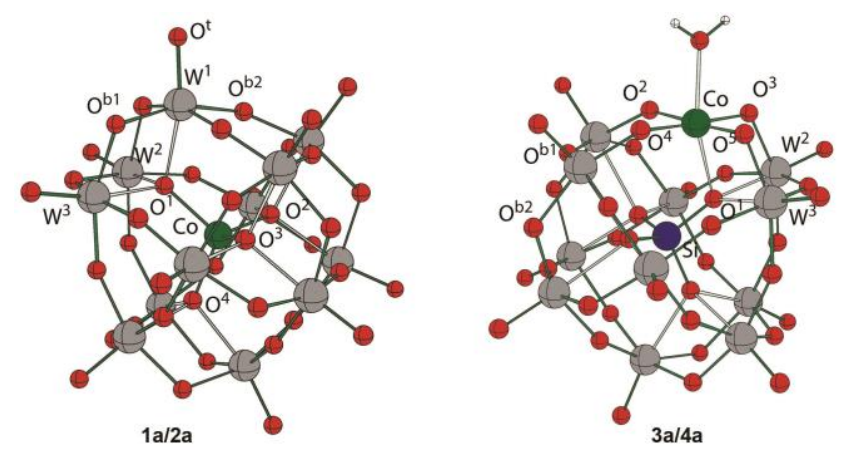

Figure 1. Calculated geometrical representations of the cluster anions $\mathbf{1 a} / \mathbf{2 a}$ and $\mathbf{3 a} \mathbf{a} \mathbf{4 a}$, with atomic labels corresponding to distances tabulated in Table 1. Color scheme: $\mathrm{W}$, gray; $\mathrm{O}$, red; $\mathrm{Co}$, green; $\mathrm{Si}$, blue.

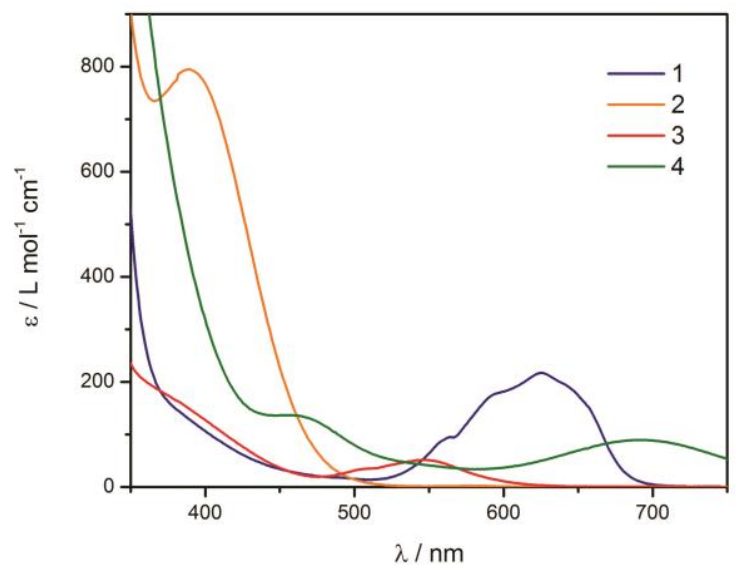

Figure 2. Visible electronic absorption spectra of 1-4 in water. 
a)

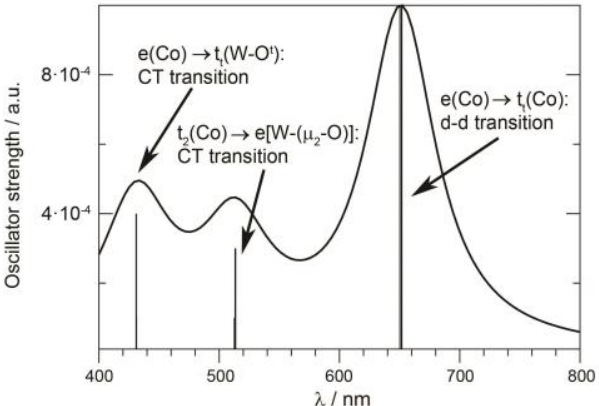

b)

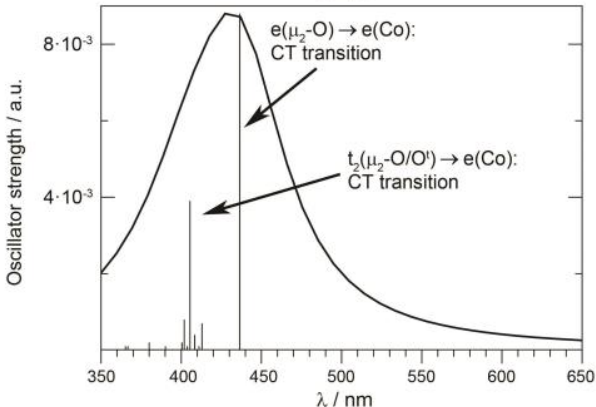

c)

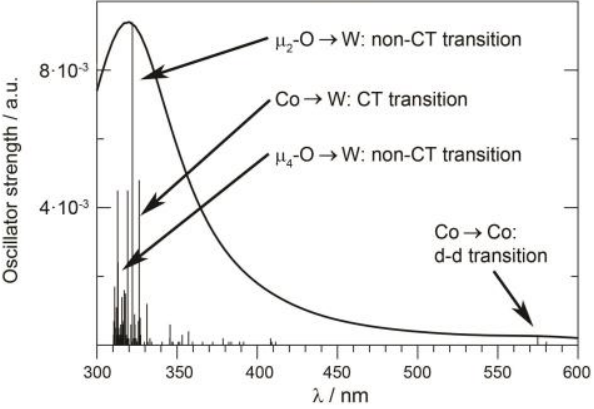

d)

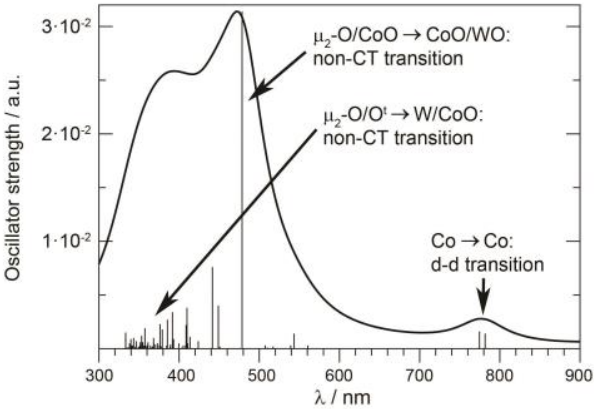

Figure 3. The calculated UV-visible spectrum of a) quartet 1a, b) quintet 2a, c) quartet 3a, and d) triplet 4a. The lines in the main feature are marked by their dominant electronic transitions. See Figures S5 and S6 for definitions of the presented frontier orbitals. 

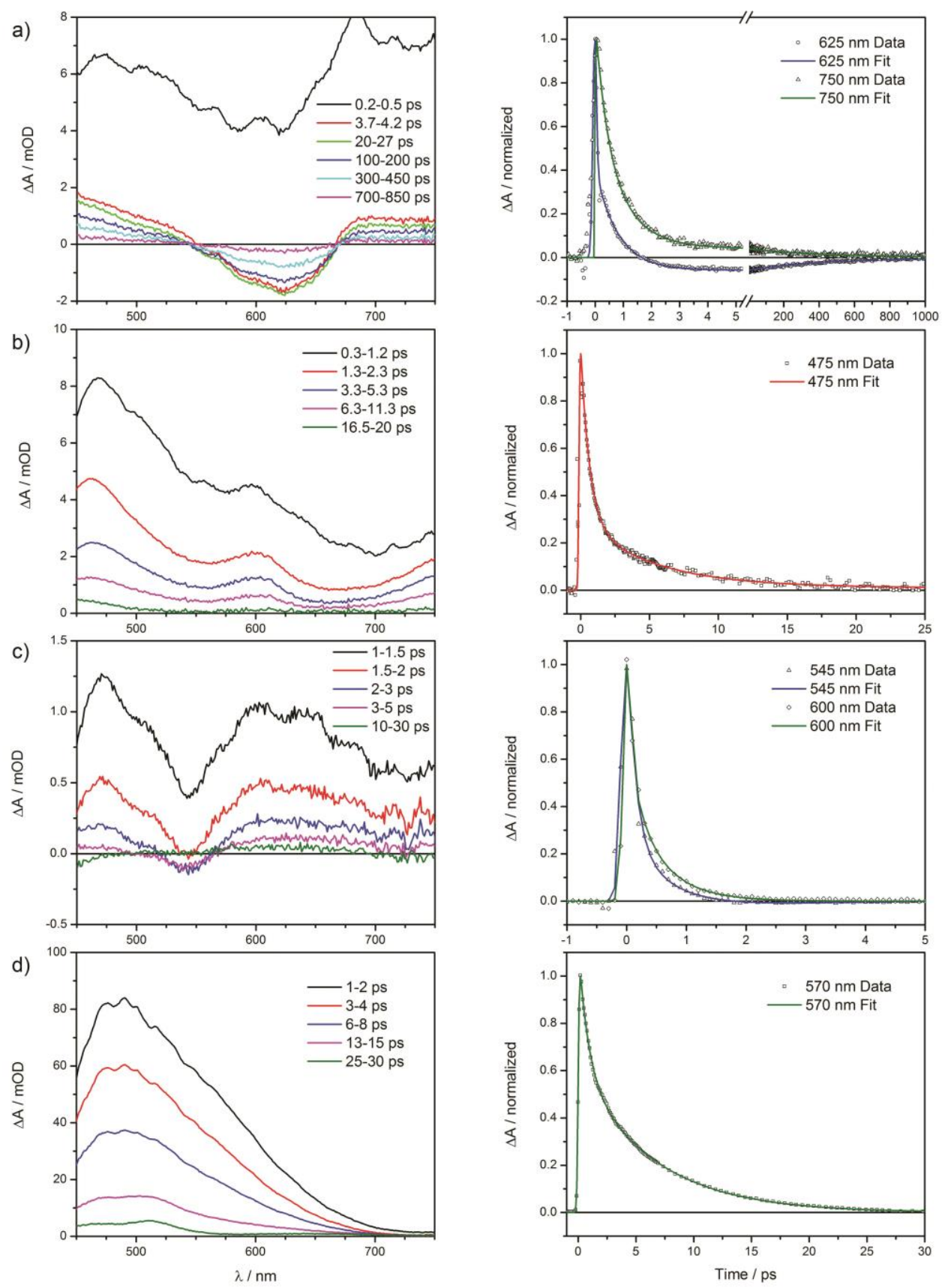

Figure 4. Transient absorption spectra (left) and kinetics (right) of: a) 1, b) 2, c) 3, and d) 4, after excitation by an ultrafast pump pulse at $400 \mathrm{~nm}$. Spectral traces are the average of multiple measurements within the noted time windows. Empirical measurements and multiexponential fits to the kinetics at representative wavelengths are shown normalized to their respective peak values. Complexes $\mathbf{1}$ and $\mathbf{2}$ are measured in $0.250 \mathrm{M}$ sodium sulfate buffer, pH 2; complexes $\mathbf{3}$ and $\mathbf{4}$ are measured in $0.250 \mathrm{M}$ lithium acetate buffer, $\mathrm{pH} 5$. 


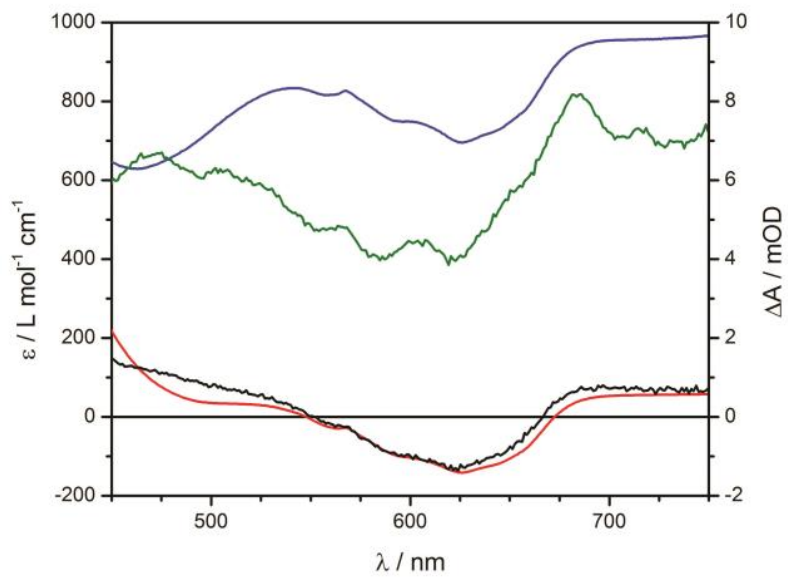

Figure 5. Comparison of the transient difference spectra of $\mathbf{1}$ and the simulated difference spectra of the excited states calculated from static ground state spectra of $\mathbf{1}$, 2 and reduced 1. The simulated heteropoly blue species (blue line) is compared to the spectra from 0.2-0.5 ps after excitation, representative of $\tau_{1}$ (green line). A simulated excited state (red line) with a smaller $\left(1 / 12^{\text {th }}\right)$ heteropoly blue contribution is compared to the transient spectra from $3.7-4.2$ ps, representative of $\tau_{2}$ (black line).

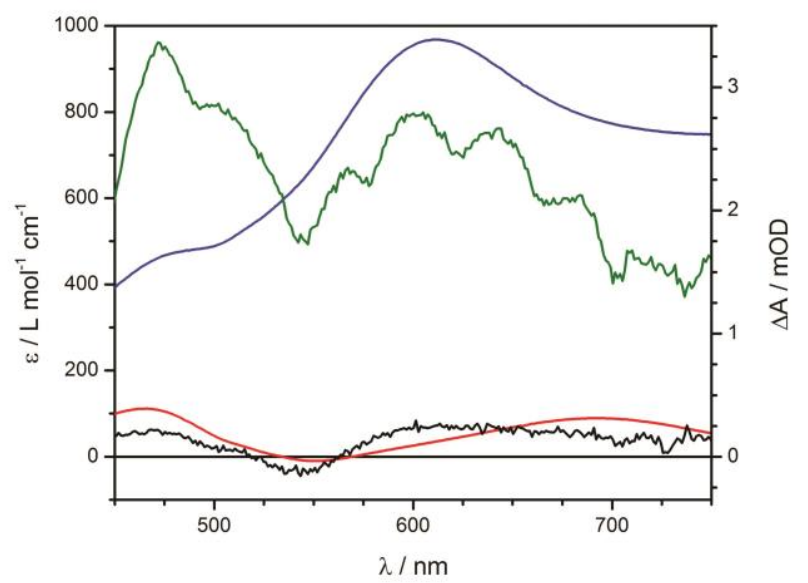

Figure 6. Comparison of the transient spectra of $\mathbf{3}$ and the simulated difference spectra of the excited states calculated from static ground state spectra of $\mathbf{3}, \mathbf{4}$ and reduced 3. The simulated heteropoly blue species (blue line) is compared to the spectra from $0.5-1.0 \mathrm{ps}$ after excitation, representative of $\tau_{1}$ (green line). A simulated excited state (red line) is compared to the transient spectra from 2.0-3.0 ps, representative of $\tau_{2}$ (black line).

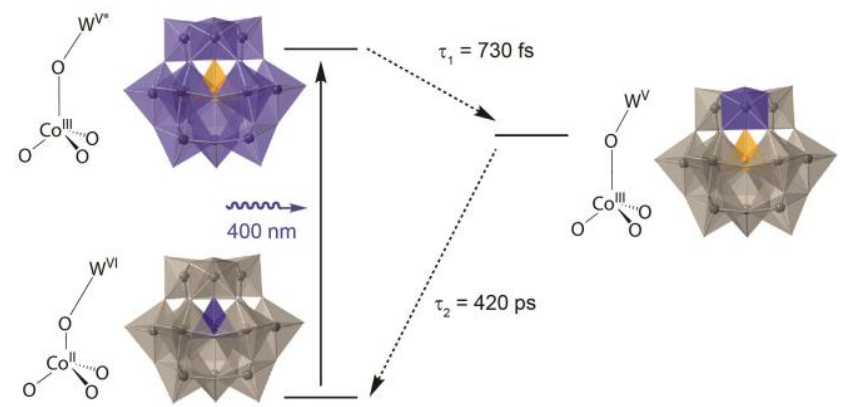

Scheme 1. Proposed excited state decay pathway for 1a illustrating the transient valence trap suggested by the long-lived excited state $\tau_{2}$. WV $*$ indicates a fully delocalized heteropoly blue state. Stick diagrams of the core tetrahedron illustrate distortion of the heteroatom environment; polyhedral representations of the complete POM indicate the position of the photoexcited electron (blue shading). 


\section{Tables}

Table 1. Experimental (crystallographic) and calculated bond lengths ( $\mathrm{A}$ ) in the cluster anions 1a, 2a, 3a and 4a. Where appropriate, crystallographically determined distances have been averaged.

\begin{tabular}{|c|c|c|c|c|c|c|}
\hline \multirow[t]{2}{*}{ Param. } & \multicolumn{2}{|c|}{ Experimental } & \multicolumn{4}{|c|}{ Computational } \\
\hline & $1 a$ & $2 a$ & $1 \mathrm{a}$ & $2 a$ & $3 \mathbf{a}$ & $4 a$ \\
\hline $\mathrm{Co}-\mathrm{O}^{1}$ & $1.900(12)$ & $1.805(5)$ & 1.92 & 1.83 & 2.08 & 2.11 \\
\hline $\mathrm{Co}-\mathrm{O}^{2}$ & & & --- & --- & 2.06 & 1.88 \\
\hline $\mathrm{Co}-\mathrm{O}^{3}$ & & & --- & --- & 2.08 & 1.88 \\
\hline $\mathrm{Co}-\mathrm{O}^{4}$ & & & --- & --- & 1.99 & 1.88 \\
\hline $\mathrm{Co}-\mathrm{O}^{5}$ & & & --- & --- & 2.00 & 1.88 \\
\hline $\mathrm{Co} / \mathrm{W}^{1}-\mathrm{O}^{1}$ & $2.137(11)$ & $2.202(5)$ & 2.20 & 2.25 & 2.08 & 2.11 \\
\hline $\mathrm{W}^{2}-\mathrm{O}^{1}$ & $2.159(12)$ & $2.216(5)$ & 2.20 & 2.25 & 2.39 & 2.36 \\
\hline $\mathrm{W}^{3}-\mathrm{O}^{1}$ & $2.165(12)$ & $2.262(5)$ & 2.20 & 2.30 & 2.42 & 2.36 \\
\hline $\mathrm{Co}-\mathrm{W}$ & $3.491(3)$ & $3.512(1)$ & 3.55 & 3.57 & --- & --- \\
\hline
\end{tabular}

Table 2. Multi-Exponential Lifetimes of Transient Absorption Decay Spectra

\begin{tabular}{ccc}
\hline Compound & \multicolumn{2}{c}{ Lifetimes } \\
\hline$\left[\mathrm{Co}^{\mathrm{II}} \mathrm{W}_{12} \mathrm{O}_{40}\right]^{6-}(\mathbf{1})$ & $\tau_{1}(\mathrm{fs})$ & $\tau_{2}(\mathrm{ps})$ \\
$\mathbf{1}$ in $\mathrm{MeCN}^{-1 \mathrm{~N}}$ & $830 \pm 40$ & $420 \pm 30$ \\
{$\left[\mathrm{Co}^{\mathrm{III}} \mathrm{W}_{12} \mathrm{O}_{40}\right]^{5-}(\mathbf{2})$} & $220 \pm 50$ & $4.4 \pm 0.6$ \\
{$\left[\mathrm{SiCo}^{\mathrm{II}}\left(\mathrm{H}_{2} \mathrm{O}\right) \mathrm{W}_{11} \mathrm{O}_{39}\right]^{6-}(\mathbf{3})^{[\mathrm{a}]}$} & $570 \pm 40$ & $1.3 \pm 3.8$ \\
{$\left[\mathrm{SiCo}^{\mathrm{III}}\left(\mathrm{H}_{2} \mathrm{O}\right) \mathrm{W}_{11} \mathrm{O}_{39}\right]^{5-}(\mathbf{4})$} & $400 \pm 150$ & $6.3 \pm 0.6$ \\
\hline
\end{tabular}

[a] Lifetime determined by single wavelength kinetics at $546 \mathrm{~nm}$

Table 3. Crystal data, data collection parameters and refinement statistics for $\mathbf{1}$ and $\mathbf{2}$. 


\begin{tabular}{|c|c|c|}
\hline & 1 & 2 \\
\hline Empirical formula & $\mathrm{CoH}_{29} \mathrm{~K}_{5} \mathrm{O}_{54} \mathrm{~W}_{12}$ & $\mathrm{CoH}_{32} \mathrm{~K}_{5} \mathrm{O}_{56} \mathrm{~W}_{12}$ \\
\hline $\mathrm{F}_{\mathrm{w}} / \mathrm{g} \mathrm{mol}^{-1}$ & 3353.86 & 3388.89 \\
\hline $\mathbf{T} / \mathbf{K}$ & $173(2)$ & $173(2)$ \\
\hline$\lambda / \AA$ & 0.71073 & 0.71073 \\
\hline Crystal system & hexagonal & hexagonal \\
\hline Space group & $\mathrm{P}_{2} 2 \mathrm{I}$ & $\mathrm{PG}_{2} 22$ \\
\hline a / $\AA$ & 18.997(1) & $18.980(3)$ \\
\hline b / A & $18.997(1)$ & $18.980(3)$ \\
\hline c/ $\mathrm{A}$ & $12.479(1)$ & $12.524(3)$ \\
\hline$\alpha /{ }^{\circ}$ & 90 & 90 \\
\hline$\beta /^{\circ}$ & 90 & 90 \\
\hline$\gamma /{ }^{\circ}$ & 120 & 120 \\
\hline $\mathbf{V} / \AA^{3}$ & $3900.1(5)$ & $3907(1)$ \\
\hline $\mathbf{Z}$ & 3 & 3 \\
\hline$\rho_{\text {calc }} / \mathrm{g} \mathrm{cm}^{-3}$ & 4.284 & 4.321 \\
\hline$\mu / \mathbf{m m}^{-1}$ & 27.248 & 27.203 \\
\hline Crystal size $/ \mathrm{mm}^{3}$ & $0.39 \times 0.39 \times 0.36$ & $0.40 \times 0.27 \times 0.16$ \\
\hline No. reflections (unique) & $44212(6874)$ & $61027(2818)$ \\
\hline $\mathbf{R}_{\text {int }}$ & 0.1093 & 0.0884 \\
\hline$\theta_{\max }$ & 29.00 & 26.91 \\
\hline Completeness to $\theta_{\max }$ & $99.3 \%$ & $99.5 \%$ \\
\hline $\begin{array}{c}\text { Data / restraints / } \\
\text { parameters }\end{array}$ & $6874 / 3 / 306$ & $2818 / 6 / 169$ \\
\hline Goodness-of-fit on $F^{2}$ & 1.064 & 1.094 \\
\hline Residuals: $\mathbf{R}_{1}$; wR $\mathbf{R}_{2}$ & $0.0506,0.1355$ & $0.0207,0.0514$ \\
\hline $\begin{array}{c}\text { Final difference peak and } \\
\text { hole / } \mathrm{e}^{-3}\end{array}$ & $1.188,-1.710$ & $0.888,-0.814$ \\
\hline
\end{tabular}

Table of Contents

Layout 1:

Metal-to-Polyoxometalate Charge

Transfer Chromophores go

Nanosecond

Elliot N. Glass, John Fielden, Alexey L. Kaledin, Djamaladdin G. Musaev, Tianquan Lian and Craig L. Hill .............. Page - Page

Extending Metal-to-

Polyoxometalate Charge Transfer

Lifetimes: The Effect of

Heterometal Location

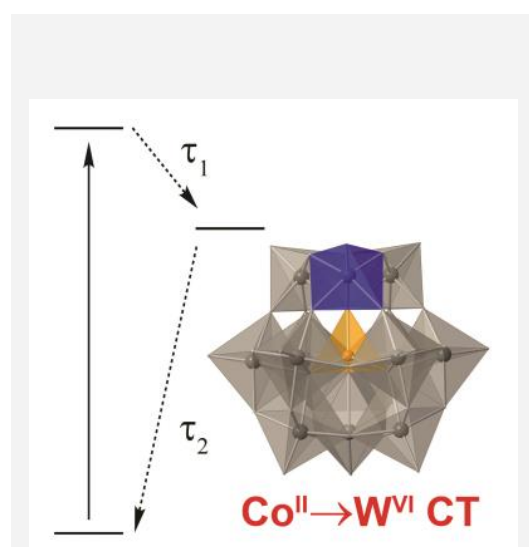

Transient absorption spectroscopy reveals that the cobalt(II)-centered Keggin anion, $\left[\mathrm{Co}^{\mathrm{II}} \mathrm{W}_{12} \mathrm{O}_{40}\right]^{6-}$, has the longest-lived metal-to-

polyoxometalate charge transfer excited state yet measured, reaching $1.7 \mathrm{~ns}$ in acetonitrile. Comparison with $\left[\mathrm{SiCo}^{\mathrm{II}}\left(\mathrm{H}_{2} \mathrm{O}\right) \mathrm{W}_{11} \mathrm{O}_{39}\right]^{6-}$ (lifetime $1.3 \mathrm{ps}$ ) indicates the importance of the central heterometal site, and the longlived state is ascribed to a valencetrapped $\mathrm{Co}^{\mathrm{III}}-\mathrm{W}^{\mathrm{V}}$ intermediate.

\section{Keywords}

Keywords: Polyoxometalates $\bullet$ Chromophores $\bullet$ Transient Absorption Spectroscopy $\bullet$ Charge Transfer $\bullet$ Valence Trapping 